\title{
PERANCANGAN TURBIN PELTON SKALA PIKO HIDRO KAPASITAS 1 KW
}

\author{
Lukman Susanto*, Tabah Priangkoso dan Darmanto \\ Jurusan Teknik Mesin, Fakultas Teknik, Universitas Wahid Hasyim Semarang \\ Jl. Menoreh Tengah X/22, Sampangan Semarang 50236 \\ *Lukmansusanto1@gmail.com
}

\begin{abstract}
Abstrak
Turbin Pelton merupakan jenis turbin yang banyak dipilih dan digunakan karena dapat diterapkan pada head dan kapasitas air yang kecil untuk pembangkit Piko Hidro. Tujuan perancangan ini adalah bagaimana merancang turbin pelton berskala piko $1 \mathrm{~kW}$ yang dapat diterapkan di daerah-daerah yang belum terjangkau dari jaringan PLN, namun mempunyai sumber energi hidro. Sebagai dasar perancangan ditetapkan kapasitas dan tinggi elevasi air jatuh yang digunakan sebesar $0,005 \mathrm{~m}^{3} / \mathrm{s}$ dan $37 \mathrm{~m}$. Perancangan turbin menggunakan nosel berukuran $15 \mathrm{~mm}$, dengan diameter aktif semburan 0,28 m. Pemisah air semburan (splitter) menggunakan sudut sebesar $24^{\circ}$ dan sudut dinding air keluar sudu sebesar $155^{\circ}$. Gaya pancaran air dari nosel dapat menghasilkan torsi sebesar 17,7 Nm pada putaran sebesar 900 rpm dengan efisiensi $80 \%$ serta daya mekanik turbin yang dapat dibangkitkan sebesar 1.334,4 Watt. Daya tersebut lebih besar dengan daya rencana yaitu 1000 Watt.
\end{abstract}

Kata kunci: Turbin Pelton, PikoHidro, Perancangan

\section{PENDAHULUAN.}

Turbin Pelton merupakan mesin konversi energi yang memanfaatkan energi potensial air menjadi energi mekanik dan diubah menjadi energi listrik. Turbin tekanan ini dapat menghasilkan daya listrik yang bervariasi, dari yang terkecil Pico Hydro hingga yang terbesar Large Hydro. Daya yang dapat dibangkitkan oleh turbin pelton dengan daya Piko Hidro adalah kurang dari $5 \mathrm{~kW}$ sedangkan $100 \mathrm{MW}$ untuk turbin berjenis Large Hydro Sopian dan Razak (2009).

Turbin Pelton banyak dipilih karena biaya yang digunakan terjangkau untuk pembuatannya. Dengan daya yang sama Turbin Pelton paling mudah dikerjakan dibandingkan jenis Turbin yang lain, dan lebih unggul yaitu praktis dalam perawatan. Efisiensi terendah Turbin Pelton adalah $80 \%$ (Keller, 1981). Sedangkan tertinggi yang dapat dicapai adalah 90\%. Lebih tingi dibandingkan pembangkit Thermal dengan efisiensi maksimal 40\% dan Turbin gas maksimal $60 \%$ (Wagner dan Mathur, 2011).

Untuk menentukan desain Turbin Pelton dengan daya $1 \mathrm{~kW}$ yaitu menetapkan potensial dan debit air. Tujuannya adalah untuk mengetahui besarnya daya hidrolik yang dapat diberikan ke Turbin Pelton. Selain itu dalam melakukan perancangan turbin pelton berskala Piko menurut Eisenring (1991), dapat dilakukan dengan menggunakan persamaan empiris seperti penentuan dimensi pada sudu
Turbin. Selain menggunakan persamaan empiris, untuk mendapatkan hasil yang optimal perancangan Turbin Pelton merujuk pada dua perancangan Turbin terdahulu. Seperti menetapkan kedalaman sudu Turbin yang merujuk dari hasil pengujian Turbin yang dilakukan oleh Priangkoso dkk. (2017) dan menetapkan sudut splitter yang merujuk pada hasil pengujian turbin oleh Chukwune dkk. (2014).

\section{METODE}

Perancangan diawali dengan menetapkan variabel utama yaitu debit air dan head, masingmasing sebesar $0,005 \mathrm{~m}^{3} / \mathrm{s}$ dan $37 \mathrm{~m}$. Penetapan kapasitas air merujuk pada data yang diunggah oleh badan pusat statistik tahun 2015, yaitu debit maka aliran air sungai yang tergolong kecil (PikoHidro) yang ada di Indonesia adalah $1 \mathrm{~m}^{3} / \mathrm{s}$. Penetapan besarnya debit air sebesar $0,005 \mathrm{~m}^{3} / \mathrm{s}$ bertujuan untuk menanggulangi ketersediaan air dan juga merujuk pada pengujian karakteristik turbin pelton yang dilakukan oleh Priangkoso dkk. (2017), yang menggunakan debit dan head sebesar $0,005 \mathrm{~m}^{3} / \mathrm{s}$ dan $37 \mathrm{~m}$.

Variabel yang telah ditetapkan digunakan untuk menetapkan dimensi sudu. Selanjutnya akan dilakukan perhitungan ulang untuk memastikan besarnya daya mekanik turbin yang dapat dibangkitkan. Hasilnya akan dibuat dalam sebuah gambar tiga dimensi untuk mempermudah dalam melakukan fabrikasi turbin pelton. 


\section{Perancangan}

Dengan variabel yang telah ditetapkan maka daya hidrolik yang dapat diberikan ke turbin dapat dihitung dengan persamaan 1 .

$$
\begin{aligned}
& P_{h}=\rho Q g H \\
& P_{h}=1000 \frac{\mathrm{kg}}{\mathrm{m}^{3}} 0,005 \frac{\mathrm{m}^{3}}{\mathrm{~s}} 9,81 \frac{\mathrm{m}^{2}}{\mathrm{~s}} 37 \mathrm{~m} \\
& P_{h}=1.814 \mathrm{Watt}
\end{aligned}
$$

Daya hidrolik tersebut tergolong PikoHidro karena di bawah $5 \mathrm{Kw}$. Dengan menetapkan koefisien nosel sebesar 0,98 (Cote, 2003). Untuk menghitung kecepatan air yang mengalir keluar nosel dengan persamaan 2 .

$$
\begin{aligned}
& C_{1}=K_{C} \sqrt{2 g H_{n}} \\
& C_{1}=0,98 \sqrt{2\left(9,81 \frac{m}{s^{2}}\right)(37 m)} \\
& C_{1}=26,4 \mathrm{~m} / \mathrm{s}
\end{aligned}
$$

\section{HASIL DAN PEMBAHASAN Diameter Nosel}

Turbin Pelton dirancang mampu menghasilkan daya mekanik sedikitnya 1000 Watt dan mampu beroperasi pada putaran 900 rpm dengan efisiensi 80\%.Efisiensi tersebut adalah efisiensi terendah turbin pelton (Keller,1981). Penetapan nilai efisiensi tersebut bertujuan untuk menanggulangi kekurangan daya. Sedangkan penetapan putaran turbin sebesar $900 \mathrm{rpm}$ bertujuan untuk menyesuaikan putaran generator satu poros yang berjenis low rpm yang mampu menghasilkan listrik pada putaran rendah yaitu sekitar $900 \mathrm{rpm}$.

Menurut Eisenring (1991), diameter outlet nosel dan besarnya diameter air semburan dapat ditentukan secara optimal dengan menggunakan kecepatan aliran air dari nosel. Yaitu dengan menggunakan persamaan 3 .

$$
\begin{aligned}
& d=\sqrt{\frac{4 Q}{Z \pi C_{1}}} \\
& d=\sqrt{\frac{4\left(0,005 \frac{\mathrm{m}^{3}}{\mathrm{~s}}\right)}{1 \pi(26,4 \mathrm{~m} / \mathrm{s})}} \\
& d=\sqrt{\frac{\left(0,02 \frac{\mathrm{m}^{3}}{\mathrm{~s}}\right)}{\left(82,94 \frac{\mathrm{m}}{\mathrm{s}}\right)}} \\
& d=0,015 \mathrm{~m}
\end{aligned}
$$

Hasil perhitungan di atas akan digunakan untuk menentukan dimensi dari sudu. Seperti dimensi lebar sudu dengan diameter outlet nosel atau diameter air jet dimana telah ditetapkan pada Tabel 1 (Eisenring, 1991).

Tabel 1 Hubungan antara diameter jet/diameter outlet nosel dengan lebar bucket Lebar bucket, Diameter outlet b (mm) nosel/air jet, d (mm)

\begin{tabular}{rl}
\hline $3-6 \mathrm{~mm}$ & $19 \mathrm{~mm}$ \\
$6-10 \mathrm{~mm}$ & $30 \mathrm{~mm}$ \\
$15-20 \mathrm{~mm}$ & $45 \mathrm{~mm}$ \\
$20-25 \mathrm{~mm}$ & $60 \mathrm{~mm}$ \\
$25-30 \mathrm{~mm}$ & $90 \mathrm{~mm}$ \\
\hline
\end{tabular}

\section{Bucket}

Dimensi sudu dapat ditetapkan dengan persamaan empiris berikut.

1) Menentukan lebar bucket, (b) $\mathrm{mm}$

$\mathrm{b}=3,2(\mathrm{~d})$

$\mathrm{b}=3,2(15 \mathrm{~mm})$

$\mathrm{b}=48,5 \mathrm{~mm}$

agar desain sudu membentuk sudut splitter (pemisah air) dengan sudut $24^{\circ}$ dansudut keluar air sebesar $155^{\circ}$ dibulatkanmenjadi 60 $\mathrm{mm}$. Serta menyesuaikan dengan tabel 1 .

2) Menentukan tinggi bucket, $\mathrm{h}(\mathrm{mm})$

$\mathrm{h}=2,7(\mathrm{~d})$

$\mathrm{h}=2,7(15 \mathrm{~mm})$

$\mathrm{h}=40,5 \mathrm{~mm}$

agar didapatkan nilai PCD 0,28 $\mathrm{m}$ (diameter aktif terkena air pancaran), maka tinggi bucket dibulatkan menjadi $55 \mathrm{~mm}$.

3) Menentukan kedalaman bucket, $\mathrm{t}(\mathrm{mm})$

$\mathrm{t}=0,9(\mathrm{~d})$

$\mathrm{t}=0,9(16 \mathrm{~mm})$

$\mathrm{t}=14,4 \mathrm{~mm}$

dibulatkan menjadi $20 \mathrm{~mm}$ agar panjang lintasan yang terkena tumbukan air dapat menerima gaya dari air lebih optimal dan menyesuaikan seperti desain yang dibuat sebelumnya oleh Priangkoso dkk. (2017).

4) Menentukan lebar celah bucket untuk jalur air jet, a (mm)

$\mathrm{a}=1,2(\mathrm{~d})$

$\mathrm{a}=1,2(15 \mathrm{~mm})$

$\mathrm{a}=18 \mathrm{~mm}$ 
dibulatkan menjadi $20 \mathrm{~mm}$ agar tidak menghalangi laju semburan air.

5) Menetapkan sudut pemisah air pancaran (splitter) $24^{\circ}$ sesuai dengan hasil terbaik dari pengujian sudut splitter (Chukwuneke dkk., 2014) dan menetapkan sudut keluar air sudu sebesar $155^{\circ}$.

\section{Diameter Runner}

Dalam perancangan ini nilai kecepatan keliling optimal $\left(\mathrm{U}_{1}\right)$ pada turbin akan digunakan untuk menentukan dimensi runner. Selanjutnya hasil dari kecepatan putar runner digunakan untuk menghitung besarnya daya yang akan dibangkitkan oleh turbin. Jika diasumsikan bahwa nilai koefisien kecepatan $\left(\mathrm{K}_{\mathrm{U}}\right)$ turbin pelton sebesar 0,49 atau sekitar setengah dari kecepatan optimal. Juga dibuktikan dengan persamaan 4 (persamaan Euler), jika dilihat dari segitiga kecepatan pada Gambar 1, besarnya $\mathrm{C}_{2(\mathrm{x})}$ bernilai nol karena arah dari $\mathrm{C}_{2(\mathrm{x})}$ tegak lurus dengan arah gerak sudu atau tidak mempengaruhi arah putaran. Oleh karena itu besarnya nilai $\mathrm{C}_{2}$ bernilai nol.

$$
\begin{aligned}
& H=\frac{\left(U_{1} C_{1}\right)-\left(U_{1} C_{2}\right)}{g \eta_{\text {Turbin }}} \\
& U_{1}=\frac{H \eta_{\text {Turbin }} g}{C_{1}} \\
& U_{1}=\frac{\eta_{\text {Turbin }} g}{C_{1}} H \\
& U_{1}=\frac{\eta_{\text {Turbin }} g}{C_{1}} \frac{C_{1}^{2}}{2 g} \\
& U_{1}=\frac{\eta_{\text {Turbin }} C_{1}}{2} \\
& U_{1}=\frac{C_{1}}{2}
\end{aligned}
$$

Kecepatan putar keliling optimal dari turbin dapat dihitung dengan persamaan 5 .

$$
\begin{aligned}
& U_{1}=0,49 \sqrt{2 g H_{n}} \\
& U_{1}=0,49 \sqrt{2\left(9,81 \frac{\mathrm{m}}{\mathrm{s}^{2}}\right)(37 \mathrm{~m})} \\
& U_{1}=13,2 \mathrm{~m} / \mathrm{s}
\end{aligned}
$$




$$
\begin{aligned}
& z=\frac{D_{r} \times \pi}{2 \times d} \\
& z=\frac{(200 \mathrm{~mm}) \times \pi}{2 \times(15 \mathrm{~mm})} \\
& z=21 \mathrm{picS}
\end{aligned}
$$

Berdasarkan persamaan empiris di atas diperoleh dimensi turbin berikut.
1. Diameter runner
: $200 \mathrm{~mm}$
2. Lebar bucket
: $60 \mathrm{~mm}$
3. Kedalaman bucket
$: 20 \mathrm{~mm}$
4. Tinggi bucket
: $55 \mathrm{~mm}$
5. Jumlah bucket
$: 21$ pics
6. Lebar celah bucket
: $20 \mathrm{~mm}$
7. Sudut splitter
$: 24^{\circ}$
8. Sudut air keluar sudu
$: 155^{\circ}$
9. Jari-jari aktif turbin (PCD)
: $140 \mathrm{~mm}$
10.Jumlah poros turbin $: 1$ poros

Untuk memperjelas bentuk dan dimensi turbin digunakan software 3D agar diperoleh bentuk turbin dalam tampilan 3 dimensi dengan hasil seperti terlihat pada Gambar 4.

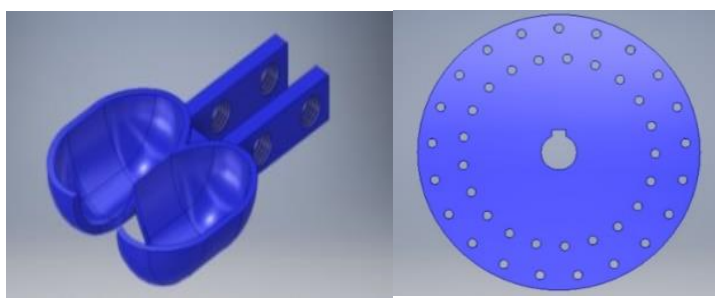

(A)

(B)

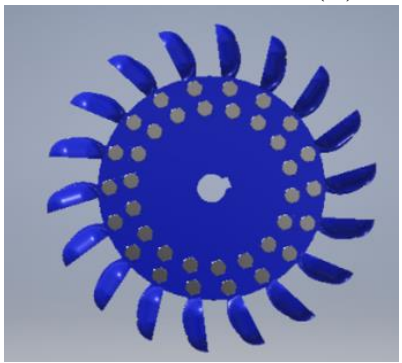

(C)

Gambar 3. (A) Desain sudu, (B) Desain runner, (C) Assembly turbin.

Selanjutnya dilakukan perhitungan ulang hasil desain untuk memeriksa kesesuaian dengan daya mekanik rencana yaitu sebesar 1000 Watt. Kecepatan air yang masuk dan keluar sudu dapat dihitung dengan mengalikan kecepatan air semburan dari nosel dengan dimensi permukaan yang dilewatinya. Aliran air pancaran yang masuk dan keluar sudu dapat dilihat Gambar 4 A.

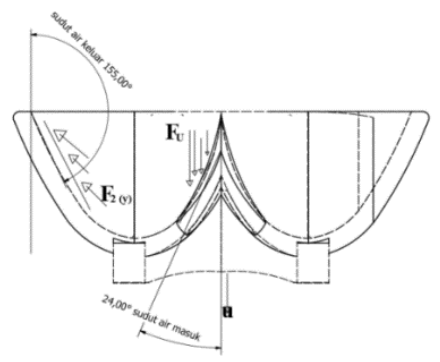

(A)

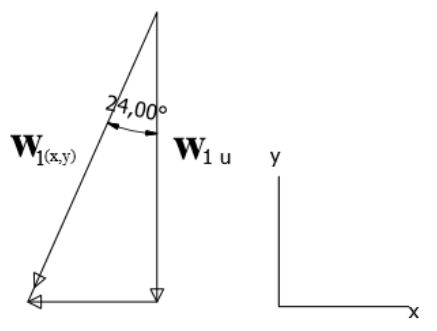

(B)

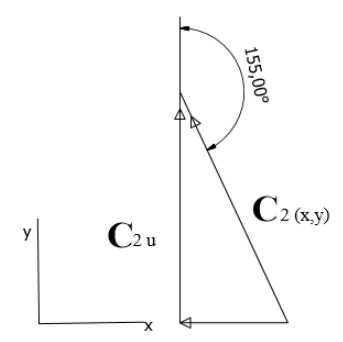

(C)

Gambar 4. (A) Model aliran air pada sudu, (B) Segitiga kecepatan air ketika masuk sudu, (C) Segitiga kecepatan air ketika keluar sudu

Jika diketahui dari gambar 4B memiliki sudut splitter $24^{\circ}$ dan kecepatan air semburan $26,4 \mathrm{~m} / \mathrm{s}$, untuk menghitung kecepatan air ketika masuk mengenai splitter dihitung dengan persamaan 8, yaitu mengalikan kecepatan air semburan dengan kemiringan sudut splitter (mengabaikan kekasaran permukaan).Kecepatan air yang akan digunakan untuk menghitung daya mekanik adalah kecepatan yang arahnya searah dengan arah putaran turbin (searah dengan sumbu y).

$$
\begin{aligned}
& W_{1(\mathrm{y})}=C_{1} \cos a \\
& W_{1(\mathrm{y})}=26,4 \cos 24 \\
& W_{1(\mathrm{y})}=24,11 \mathrm{~m} / \mathrm{s}
\end{aligned}
$$

Sedangkan untuk menghitung kecepatan air yang arahnya sejajar dengan arah putaran turbin ketika meninggalkan sudu, dapat dihitung dengan persamaan 9, yaitu mengalikan kecepatan 
air yang telah melewati splitter dengan sudut keluar air ketika meninggalkan sudu.

$$
\begin{aligned}
& C_{2(\mathrm{y})}=W_{1(\mathrm{y})} \cos a \\
& C_{2(\mathrm{y})}=24,11 \cos 155 \\
& C_{2(\mathrm{y})}=-21,85 \mathrm{~m} / \mathrm{s}
\end{aligned}
$$

Untuk menghitung gaya air pancaran yang mengenai sudu sisi masuk dapat dihitung dengan persamaan 10 , yaitu mengalikan massa air yang keluar dari nosel dengan perubahan kecepatan air ketika masuk sudu (mengenai splitter)

$$
\begin{aligned}
& F_{1(y)}=M W_{1(y)} \\
& F_{1(y)}=\rho A C_{1} W_{1(y)} \\
& F_{1(y)}=\left(1000 \frac{\mathrm{kg}}{\mathrm{m}^{3}}\right)\left(\frac{\pi}{4}(0,015 \mathrm{~m})^{2}\right)(26,4 \mathrm{~m} / \mathrm{s})(24,11 \mathrm{~m} / \mathrm{s}) \\
& F_{1(y)}=108,2 \mathrm{~N}
\end{aligned}
$$

Sedangkan gaya yang bekerja ketika meninggalkan sudu dapat dihitung dengan persamaan 11.

$$
\begin{aligned}
& F_{1(y)}=M W_{1(y)} \\
& F_{1(y)}=\rho A C_{1} W_{1(y)} \\
& F_{1(y)}=\left(1000 \frac{\mathrm{kg}}{\mathrm{m}^{3}}\right)\left(\frac{\pi}{4}(0,015 \mathrm{~m})^{2}\right)(24,11 \mathrm{~m} / \mathrm{s})(-21,85 \mathrm{~m} / \mathrm{s}) \\
& F_{1(y)}=-89,55 \mathrm{~N}
\end{aligned}
$$

Gaya yang bekerja pada sudu ke arah putaran turbin (U) dapat dihitung dengan persamaan 12 .

$$
\begin{aligned}
& F_{u}=M\left(C_{1}-\left(C_{2}\right)\right. \\
& F_{u}=\left(1000 \frac{\mathrm{kg}}{\mathrm{m}^{3}}\right)\left(\frac{\pi}{4}(0,0015 \mathrm{~m})^{2}\right)(26,4 \mathrm{~m} / \mathrm{s})(26,4 \mathrm{~m} / \mathrm{s}+21,85 \mathrm{~m} / \mathrm{s}) \\
& F_{u}=216,16 \mathrm{~N}
\end{aligned}
$$

Bentuk aliran dan distribusi gaya akibat air jet yang mengenai sebuah sudu dapat dilihat pada Gambar 6. Yaitu besarnya gaya yang masuk mengenai sudu $\left(\mathrm{F}_{\mathrm{U}}\right)$ dan gaya yang arahnya keluar meninggalkan sudu Turbin $\mathrm{F}_{2(\mathrm{y})}$. Gaya neto $(\mathrm{F})$ yang bekerja pada sebuah sudu adalah gaya $\left(\mathrm{F}_{\mathrm{U}}\right)$ yang besarnya dikurangi dengan gaya geser dari $\mathrm{F}_{2(\mathrm{y})}$. Untuk menghitung gaya netto tersebut dapat dihitung menggunakan persamaan 13.

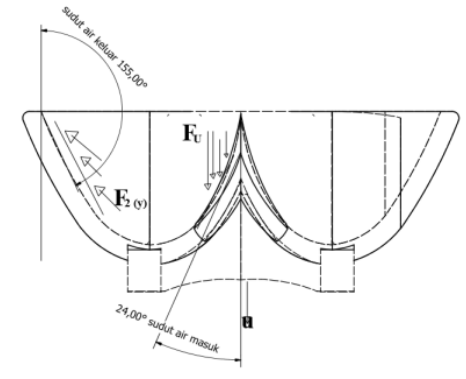

\section{Gambar 6. Distribusi gaya akibat semburan air jet pada sudu turbin pelton}

$$
\begin{aligned}
& F=F_{u}-F_{2(\mathrm{y})} \\
& F=216,16 N-89,55 N \\
& F=126 N
\end{aligned}
$$

Gaya neto tersebut dapat digunakan untuk menghitung torsi pada turbin rancangan dengan menggunakan persamaan 14, Yaitu dengan mengalikan jari-jari turbin yang terkena pancaran dengan gaya neto.

$$
\begin{aligned}
& T=r_{\text {turbin }} F \\
& T=\frac{D_{\text {turbin }}}{2} F \\
& T=\frac{0,28 m}{2} 126 N \\
& T=17,7 \mathrm{Nm}
\end{aligned}
$$

Putaran Turbin dapat dihitung dengan persamaan 15.

$$
\begin{aligned}
& n_{t}=\frac{60 U_{1}}{\pi D} \\
& n_{t}=\frac{6013,2 \mathrm{~m} / \mathrm{s}}{\pi 0,28 \mathrm{~m}} \\
& n_{t}=900 \mathrm{rpm}
\end{aligned}
$$

Jika diasumsikan turbin yang berputar tersebut memilik efisiensi $80 \%$ akibat faktor lingkungan seperti genangan air pada rumah turbin. Maka daya mekanik Turbin yang dihasilkan adalah dengan persamaan 16, yaitu mengalikan torsi yang bekerja dengan putaran turbin dan efisiensi. 


$$
\begin{aligned}
P_{t} & =\frac{2 \pi n_{t} T}{60} \eta_{\text {turbin }} \\
P_{t} & =\frac{2 \pi(900 \mathrm{rpm})(17,7 \mathrm{Nm})}{60} 80 \% \\
P_{t} & =1.334,4 \mathrm{Watt}
\end{aligned}
$$

Dengan didapatkannya nilai daya mekanik yang dihasilkan oleh turbin, maka akan sesuai dengan rancangan awal yaitu sebesar 1000 Watt. Oleh karena itu dapat dilanjutkan pada proses fabrikasi.

\section{KESIMPULAN}

Dari perhitungan ulang yang dilakukan bahwa daya mekanik turbin yang dapat dibangkitkan sebesar 1.334,4 Watt. Sesuai dengan daya yang direncanakan sebelumnya yaitu sebesar 1000 Watt. pada putaran sedikitnya $900 \mathrm{rpm}$.

\section{SARAN}

Agar perancangan turbin pelton mendapatkan hasil yang optimal, sebaiknya memperhatikan beberapa hal dalam melakukan perancangan diantaranya

1. Memperhatikan faktor gesekan terhadap air yang melintasi sudu turbin pelton.

2. Menghitung rugi-rugi yang lebih detail sehingga daya aktual dari turbin pelton dapat diketahui.

3. Menentukan posisi nosel pada jarak yang optimal. Agar distribusi gaya yang disemburkan air ke sudu menjadi optimal.

\section{DAFTAR PUSTAKA}

Aninomous, 2017, Rata-rata Harian Aliran Sungai, Tinggi Aliran, dan Beberapa Sungai Yang Daerah Pengalirannya Lebih Dari $100 \mathrm{~m}^{2}$ 2015,https://www.bps.go.id

Chukwune, J.L., Achebe, C.H., Okoli, P.C., Okwudibe, H.A, 2014, Experimental Investigation on Effect Head and Bucket Splitter Angel on the Power Output of aPelton Turbine, International Journal of Energi Engineering(IJEE)/DOI: 10.5923/j.ijee.20140404.03, Awka Nigeria.

Cote, A.E., 2003, Pengoperasian sistem proteksi kebakaran, Quncy, Massachusetts USA.

Eisenring,M. and Niederuzwile, 1991, Micro Pelton Turbine, SKAT (Swiss Center for
Appropnate Technology, St. Gallen, Switzerland.

Keller, S., 1981, Debit Air dan Spesifikasi Sistem Tekanan Tinggi dalam Perencanaan Proyek dan Desain PLTA Berkapasitas Kecil, Publikasi oleh Prof. Dr. S.Radler, University for Soil Culture, Institute for Management Water, Viena.

Priangkoso., Mustaqim, A., Malik, A., Heriyanto, 2017, Uji Efisiensi Turbin Pelton Dengan Sudu Setengah Pipa Elbow, Momentum,vol.13, No 02, Oktober 2017, Hal 25-29, Semarang.

Sopian, K. And Juhari Ab. Razak, 2009, Pico Hydro: Clean Power From Small Streams, Proceeding of the 3rd WSEAS Int. Conf. on Renewable Energy Sources, ISSN: 1790-5095.

Wagner, H. J. and Mathur, J., 2011, Introduction to hydro energy systems: Basics, technology and operation, Springer Heidelberg Dordrecht London New York. 